\title{
Área foliar especifica e teor de água para diferentes componentes foliares em espécies de Cerrado
}

\author{
Gabriel Venâncio Pereira Mariano ${ }^{*}$, Vanuza Pereira Garcia da Silva ${ }^{1}$, Maurício Batista Ávila Almeida ${ }^{1}$, \\ Vitor de Oliveira Santiago ${ }^{1}$, Murillo de Carvalho Araújo do Carmo ${ }^{1}$, Vagner Santiago do Vale ${ }^{1}$
}

RESUMO: Para a aferição dos traços funcionais e características morfofisiológicas vegetais, não há distinção entre seus componentes foliares (limbo, pecíolo e nervura principal), o que torna os resultados questionáveis. Por essa razão, o objetivo deste estudo foi avaliar, para espécies de Cerrado, qual a relevância de cada componente foliar na aferição da área foliar especifica e do teor de água nas folhas. Foram avaliadas 13 espécies de Cerrado, sendo N. amostral= 10 folhas e 5 a 10 indivíduos. Com auxílio do software ImageJ, após isolados pecíolo, nervura principal e limbo, foram mensuradas suas respectivas áreas e obtidas as massas frescas, em balança de precisão. Depois, estas foram secas em estufa a $70^{\circ} \mathrm{C}$, por $72 \mathrm{~h}$. Foram calculadas a área foliar específica, teor de água e porcentagem de massa fresca. A partir daí, foram desenvolvidas regressões para comparar a relação do teor de água pela quantidade de área foliar. Annona coriacea Mart., Dalbergia miscolobium (Benth.), Rudgea virburnoides (Cham.) Benth e Terminalia argentea Mart. \& Zucc. foram as espécies que apresentaram uma contribuição do limbo para a massa foliar superior a $80 \%$. As peças foliares devem ser separadas para aferição da área foliar específica, a fỉm de evitar alterações nos resultados finais. Com relação ao teor de água, a nervura principal foi a estrutura que melhor apresentou acúmulos de água.

Palavras-chave: traços foliares, fisiologia vegetal, características morfofisiológicas.

\section{Specific leaf area and water content for different leaf components in Cerrado species}

\begin{abstract}
In order to measure functional traits and plant morphophysiological characteristics, there is no distinction between its leaf components (limbus, petiole and main vein), which makes the results questionable. For this reason, the objective of this study was to evaluate, for Cerrado species, the relevance of each leaf component in the measurement of the specific leaf area and the water content in the leaves. Thirteen species of Cerrado were evaluated, being N. sampler $=10$ leaves and 5 to 10 individuals. With the aid of ImageJ software, after petiole, main vein and limbus isolates, their respective areas were measured and the fresh masses were obtained, in a precision scale. These were then dried in an oven at $70^{\circ} \mathrm{C}$ for $72 \mathrm{~h}$. The specific leaf area, water content and percentage of fresh mass were calculated. From this, regressions were developed to compare the relationship of the water content by the amount of leaf area. Annona coriacea Mart., Dalbergia miscolobium (Benth.), Rudgea virburnoides (Cham.) Benth and Terminalia argentea Mart. \& Zucc. were the species that presented a contribution of the limb to the foliar mass superior to $80 \%$. The leaf pieces should be separated to measure the specific leaf area in order to avoid changes in the final results. Regarding water content, the main vein was the structure that best presented accumulations of water.
\end{abstract}

Keywords: leaf traits, plant physiology, morphophysiological characteristics.

\section{INTRODUÇÃO}

As folhas são responsáveis pela respiração das plantas, e a área foliar específica (AFE - relação entre a área foliar e a massa seca da folha) é utilizado como indicador de alocação do carbono e seus efeitos no desenvolvimento vegetal (LOBO et al., 2010). Através de alterações anatômicas que ocorrem nas folhas é possível que a planta se adapte ás condições adversas no ambiente (GOBBI et al., 2011).

Mesmo com altos índices de irradiação (1500 a $\left.2500 \mu \mathrm{mol} . \mathrm{m}^{-2} \cdot \mathrm{s}^{-1}\right)$, temperatura elevada $\left(25-40{ }^{\circ} \mathrm{C}\right.$ ao meio-dia) e baixa umidade relativa do ar (1020\%) na estação seca, o Cerrado é um dos grandes centros de biodiversidade de fauna e flora
(PALHARES et al., 2010). E fatores ambientais como a disponibilidade de água e nutrientes são limitadores de crescimento da vegetação (FURQUIM et al., 2018).

Temperaturas foliares elevadas afetam a troca gasosa de forma indireta, causando estresse por razões como alterações na condutância estomática e distúrbios no mecanismo fotossintético (SAGE \& KUBIEN, 2007). O estresse hídrico associado com a temperatura alta da área foliar são fatores que podem reduzir de forma severa o desenvolvimento das plantas, pois a demanda de água está relacionada diretamente com a assimilação de gás carbônico (QADERI et al., 2012), o que levanta em questão a

\footnotetext{
Recebido em 05/07/2019, Aceito para publicação em 15/10/2019

${ }^{1}$ Universidade Estadual de Goiás (UEG)

*e-mail: gabrielvenancio_@outlook.com
} 
eficiência da planta em abastecer água suficiente (SILVA et al., 2013).

Estudos relacionados a traços funcionais analisam a área foliar específica como a razão entre a área foliar e a massa seca da folha (MARTINS, 2015) sem distinção de forma morfológica o limbo em pecíolo e nervura. Pela dificuldade de todo o processo de retirada do pecíolo e nervura principal para a medição de área foliar (BIANCO et al., 2007), em consideração a demanda de mão-de-obra e equipamentos necessários é importante estudos que justifiquem ou não a distinção da área foliar. Por essa razão, o propósito deste estudo foi avaliar se, para espécies de Cerrado, qual a relevância de cada componente foliar na aferição da área foliar especifica e do teor de água nas folhas.

\section{MATERIAL E MÉTODOS}

O estudo foi conduzido no município de Urutaí, estado de Goiás entre o período de março a junho de 2018. Para as mensurações foram coletadas amostras foliares de Annona coriacea Mart.; Aspidosperma tomentosum Mart.; Cordiera sessilis (Vell.) Kuntze; Curatella americana L.; Dalbergia miscolobium (Benth.); Emmotum nitens (Benth.) Miers; Himatanthus obovatus (Müll. Arg.) Woodson; Kielmeyera coriacea Mart. \& Zucc.; Qualea grandiflora Mart.; Roupala montana Aubl.; Rudgea virburnoides (Cham.) Benth.; Terminalia argentea Mart. \& Zucc. e Xylopia aromatica (Lam.) Mart., espécies de ambiente que predominam o bioma Cerrado. Cada espécie teve um $\mathrm{N}$ amostral de 10 folhas e 5 a 10 indivíduos. As folhas selecionadas foram de árvores adultas, totalmente expandidas e sem danos marcantes por herbívora, doenças e pragas.

Em busca de mensurar as características específicas, foram separados o pecíolo e nervura principal do limbo foliar e com o programa ImageJ obteve-se as medidas de suas respectivas áreas. Após a aferição das áreas, o pecíolo, o limbo e a nervura principal tiveram suas massas frescas (MF) quantificadas em balança de precisão e secadas em estufa a $70^{\circ} \mathrm{C}$ por 72 horas para uma nova quantificação das suas massas secas (MS). Os cálculos para análise da área foliar específica (AFE)(Equação 1), teor de água de cada parte da folha (Equação 2) e porcentagem de massa fresca para limbo, nervura principal e pecíolo (Equação 3) seguem abaixo:

$$
\begin{array}{ll}
A F E\left(m g / m^{2}\right)=\frac{A F}{M S} & (\text { Equação 1) } \\
\text { Teor de Água }(\%)=\frac{M F-M S}{M F} \times 100 & \text { (Equação 2) } \\
M F(\%)=\frac{M F}{M F t} \times 100 & \text { (Equação 3) }
\end{array}
$$

em que: $\mathrm{AFE}$ = Área foliar específica; $\mathrm{AF}=$ Área Foliar; $\mathrm{MS}=$ Massa seca; $\mathrm{MF}=$ Massa fresca do limbo, pecíolo ou nervura; $\mathrm{MFt}=$ Massa fresca total.

A partir das fórmulas foram desenvolvidas regressões para comparar a relação do teor de água pela quantidade de massa fresca em cada componente foliar: limbo, pecíolo e nervura principal.

\section{RESULTADOS E DISCUSSÃO}

A área foliar específica das espécies avaliadas, apresentou variações, entre 5 e $15 \mathrm{mg} / \mathrm{mm} 2$ (Tabela 1). Para todas as espécies avaliadas, a relação entre a massa do limbo e massa total da folha foi superior a $66 \%$. Este fato permite aferir que a massa do limbo isolada corresponde a mais da metade da massa total da folha. No entanto, o pecíolo e a nervura principal fazem parte de mais de $30 \%$ da massa da folha completa para algumas espécies, o que altera a AFE, caso quantificados juntos com o limbo.

Annona coriacea Mart., Dalbergia miscolobium (Benth.), Rudgea virburnoides (Cham.) Benth e Terminalia argentea Mart. \& Zucc. apresentaram os maiores valores de contribuição do limbo para a massa foliar, superiores a $80 \%$ (Tabela 2). Esta estrutura é a parte responsável pela concentração das moléculas de clorofila e demais nutrientes utilizados nos processos metabólicos das plantas (KIRST et al., 2017). Logo, quanto maior a área e a massa, do limbo, maior será o acúmulo de elementos e produção de fotossintéticos, o que evidencia elevados níveis de atividade fotossintética para essas espécies de Cerrado. Os menores valores de contribuição do limbo para a folha foram para as espécies Aspidosperma tomentosum Mart., Himatanthus obovatus (Müll. Arg.) Woodson e Kielmeyera coriacea Mart. \& Zucc., todas espécies com elevados níveis de exsudados, o que aumenta a quantidade de água e o valor total da massa do pecíolo e da nervura principal.

Houve uma variação entre os dados encontrados para área foliar específica entre as espécies do trabalho em comparação a outros (Tabela 1). Todas as espécies comparadas com Batalha et al., 2011, e Franco et al., 2005, apresentaram maiores AFEs. Provavelmente as diferentes épocas de coleta dos materiais vegetais tenham influenciado nestes resultados. No nosso estudo as folhas foram coletadas no final de março e início de abril (final da estação chuvosa), período de expansão máxima das folhas.

Os demais estudos, as coletas foram realizadas no pico (junho e agosto, Batalha et al., 2011) e início das chuvas (setembro a novembro, Franco et al., 2005). As variações na época de coleta podem 
alterar o tamanho das AFEs por interferirem diretamente no amadurecimento da folha. Ao considerar-se que, os períodos de floração e brotação das espécies nativas do Cerrado acontecem, principalmente, entre a troca de estação seca para estação chuvosa (PILON et al., 2015), o

Tabela 1 - Dados de área foliar específica (AFE) em $\mathrm{mg} / \mathrm{mm}^{2}$ das espécies de Cerrado obtidas no estudo em comparação com outros trabalhos (AFE') que utilizaram as mesmas espécies.

\begin{tabular}{lccc}
\hline \multicolumn{1}{c}{ Espécies } & AFE $\left(\mathbf{m g} / \mathbf{m m}^{2}\right)$ & AFE' $\left(\mathbf{m g} / \mathbf{m m}^{2}\right)$ & Referências \\
\hline Annona coriacea Mart. & 4,15 & - & - \\
Aspidosperma tomentosum Mart. & 15,06 & 7,23 & BATALHA et al., 2011 \\
Cordiera sessilis (Vell.) Kuntze & 7,28 & 12,07 & PRADO JÚNIOR, 2012 \\
Curatella americana L. & 7,40 & - & - \\
Dalbergia miscolobium (Benth.) & 9,14 & 8,67 & FRANCO et al., 2005 \\
Emmotum nitens (Benth.) Miers & 9,27 & - & - \\
Hymatanthus obovatus (Müll. Arg.) Woodson & 11,61 & - & - \\
Kielmeyera coriacea Mart. \& Zucc & 9,22 & 5,90 & BATALHA et al., 2011 \\
Qualea grandiflora Mart. & 9,51 & 7,77 & FRANCO et al., 2005 \\
Roupala montana Aubl. & 6,10 & 4,12 & FRANCO et al., 2005 \\
Rudgea virburnoides (Cham.) Benth & 8,33 & 8,98 & ARANTES, 2012 \\
Terminalia argentea Mart. \& Zucc & 12,91 & - & - \\
Xylopia aromatica (Lam.) Mart. & 15,90 & 8,69 & FERREIRA et al., 2013 \\
\hline
\end{tabular}

A utilização do pecíolo e nervura principal no cálculo de área foliar específica está subestimando a AFE real da folha (onde somente o limbo foi contabilizado como área foliar). Por não serem materiais que participam da fotossíntese da planta de forma direta (MARTINS, 2009) e terem grande recomendado é que as coletas sejam realizadas no final da estação chuvosa, sobretudo no mês de abril, período em que a queda das folhas não ocorreu e as mesmas tem mais chances de estarem totalmente expandidas..

Tabela 2 - Área foliar e características foliares das espécies mensuradas de forma separada, desde o limbo, nervura principal e pecíolo. AF $=$ Área Foliar; MFF = Massa fresca da folha; MFP = Massa fresca do pecíolo; MFNP = Massa fresca da nervura principal; MFL = Massa fresca do limbo; MSF = Massa seca a folha; MSP = Massa seca do pecíolo; MSNP = Massa seca da nervura principal e MSL = Massa seca do limbo.

\begin{tabular}{|c|c|c|c|c|c|c|c|c|c|}
\hline Espécies & $\mathbf{A F}\left(\mathrm{cm}^{2}\right)$ & $\operatorname{MFF}(\mathrm{g})$ & $\operatorname{MFP}(\mathrm{g})$ & $\operatorname{MFNP}(\mathrm{g})$ & MFL(g) & $\operatorname{MSF}(\mathrm{g})$ & $\operatorname{MSP}(\mathrm{g})$ & $\operatorname{MSNP}(\mathrm{g})$ & $\operatorname{MSL}(\mathrm{g})$ \\
\hline $\begin{array}{l}\text { Annona coriacea Mart. } \\
\text { Aspidosperma tomentosum }\end{array}$ & 65,245 & 4,415 & 0,140 & 0,548 & 3,660 & 1,641 & 0,001 & 0,183 & 1,458 \\
\hline $\begin{array}{c}\text { Mart. } \\
\text { Cordiera sessilis (Vell.) }\end{array}$ & 97,416 & 3,420 & 0,010 & 1,098 & 2,203 & 0,674 & 0,001 & 0,168 & 0,505 \\
\hline Kuntze & 89,739 & 2,421 & 0,197 & 0,440 & 1,784 & 1,297 & 0,092 & 0,235 & 0,971 \\
\hline $\begin{array}{l}\text { Curatella americana } \mathrm{L} . \\
\text { Dalbergia miscolobium }\end{array}$ & 55,800 & 5,236 & 0,942 & 0,862 & 4,094 & 0,967 & 0,001 & 0,114 & 0,852 \\
\hline $\begin{array}{c}\text { (Benth.) } \\
\text { Emmotum nitens (Benth.) }\end{array}$ & 239,696 & 5,686 & 0,145 & 0,416 & 5,126 & 2,658 & 0,101 & 0,246 & 2,311 \\
\hline $\begin{array}{c}\text { Miers } \\
\text { Hymatanthus obovatus }\end{array}$ & 56,136 & 2,310 & 0,082 & 0,324 & 1,816 & 0,619 & 0,001 & 0,056 & 0,562 \\
\hline $\begin{array}{l}\text { (Müll. Arg.) Woodson } \\
\text { Kielmeyera coriacea Mart. }\end{array}$ & 115,878 & 6,202 & 0,466 & 1,850 & 4,320 & 1,109 & 0,001 & 0,250 & 0,858 \\
\hline$\&$ Zucc & 64,676 & 6,140 & 1,060 & 1,792 & 4,060 & 0,745 & 0,001 & 0,172 & 0,572 \\
\hline Qualea grandiflora Mart. & 84,436 & 3,254 & 0,090 & 0,624 & 2,502 & 0,911 & 0,001 & 0,130 & 0,780 \\
\hline $\begin{array}{l}\text { Roupala montana Aubl. } \\
\text { Rudgea virburnoides }\end{array}$ & 64,961 & 2,369 & 0,175 & 0,317 & 1,871 & 1,120 & 0,063 & 0,130 & 0,927 \\
\hline $\begin{array}{l}\text { (Cham.) Benth } \\
\text { Terminalia argentea Mart. \& }\end{array}$ & 128,071 & 5,093 & 0,160 & 0,700 & 4,233 & 1,775 & 0,036 & 0,125 & 1,615 \\
\hline $\begin{array}{c}\text { Zucc } \\
\text { Xylopia aromatica (Lam.) }\end{array}$ & 63,192 & 1,383 & 0,073 & 0,203 & 1,130 & 0,491 & 0,001 & 0,073 & 0,417 \\
\hline Mart. & 31,762 & 0,498 & 0,001 & 0,050 & 0,398 & 0,219 & 0,001 & 0,004 & 0,214 \\
\hline
\end{tabular}


Analisados os resultados obtidos para calcular o teor de água, o limbo foliar apresentou relação negativa para as espécies deste estudo (Figura 1A, p $<0,05)$. Logo, quanto maior a área do limbo, menor a quantidade de água na folha como um todo. Isto, devido ao excesso de água no limbo, local do aparato fotossintético ser prejudicial ao seu funcionamento adequado (PALHARES et al., 2010), por dificultar a assimilação de moléculas, especialmente as fotossintéticas (LI et al., 2013).
O pecíolo não foi significativo em relação ao teor de água na folha (Figura $1 \mathrm{~B}, \mathrm{p}=0,40$ ). Com relação ao teor de água, a nervura principal foi positivamente relacionada (Figura 1B e 1C, p < $0,05)$. É possível observar um maior acúmulo na nervura principal, caracterizando uma reserva que melhoraria a eficiência no uso da água pela planta, para fins de hidratação, facilitando a abertura dos estômatos (MACHADO et al., 2009).
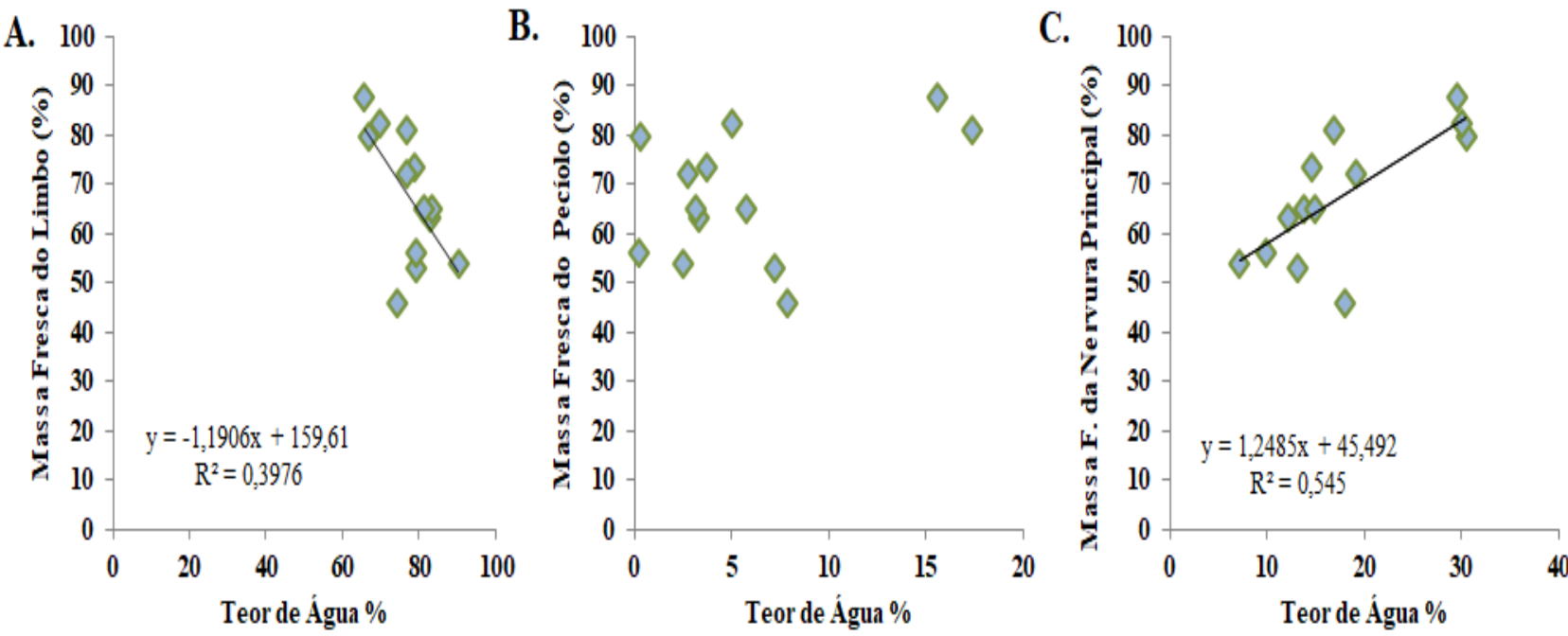

Figura 1 - Gráfico de dispersão gerados através das fórmulas da porcentagem massa fresca do limbo, pecíolo e da nervura principal em relação ao teor de água (\%) para cada uma das massas. A. Massa Fresca do Limbo (\%) x Teor de Água (\%); B. Massa Fresca do Pecíolo (\%) x Teor de Água (\%); C. Massa Fresca da Nervura Principal x Teor de Água (\%).

\section{CONCLUSÃO}

Separar o limbo, o pecíolo e a nervura principal deve ser o procedimento adequado para aferição de área foliar específica para espécies de Cerrado. A nervura principal aumenta o teor de água na folha, sendo o real local de reserva de água. Assim, estudos com foco para utilização de água pela planta devem considerar separar o limbo do pecíolo e, especialmente, da nervura principal.

\section{REFERÊNCIAS}

ARANTES, C. S. Colonização de ambientes abertos do cerrado por espécies arbóreas florestais: a ação facilitadora de Bowdichia virgilioides Kunth. 2012. 63 f. (Mestre em Ecologia e Conservação de Recursos Naturais) - Universidade Federal de Uberlândia Uberlândia, Minas Gerais.

BATALHA, M. A.; SILVA, I. A.; CIANCIARUSO, M. V.; CARVALHO, G. H. Trait diversity on the phylogeny of cerrado woody species. Oikos, v.1, p. 1-11, 2011.

BIANCO, S.; BIANCO, M. S.; PAVANI, M. C. M. D.; DUARTE, D. J. Estimativa de Área Foliar de Ipomoea hederifolia e Ipomoea nil Roth. Usando dimensões lineares do Limbo Foliar. Planta Daninha, Viçosa-MG, v. 25, n. 2, p. 325-329, 2007.
FERREIRA, G.; SCHIAVINI, I.; PRADO JÚNIOR, J. A.; MELO, C. Plastic responses in tree architecture and specific leaf area of Xylopia aromatica (Annonaceae): Adaptations to environments with different light intensities. Brazilian Journal of Botany, v. 36, n. 4, p. 279-283, 2013.

FRANCO, A. C.; GOLDSTEIN, G.; BUSTAMANTE, M. M. C.; KOZOVITS, A. R. Leaf functional traits of Neotropical savanna trees in relation to seasonal water deficit. Trees, v. 19, p. 326-335, 2005.

FURQUIM, L. C.; SANTOS, M. P.; ANDRADE, C. A. O.; OLIVEIRA, L. A.; EVANGELISTA, A. W. P. Relação entre plantas nativas do cerrado e água. Científica, v. 5, n. 2, p. 146-156, 2018.

GOBBI, K. F.; GARCIA, R.; VENTRELLA, M. C.; GRACEZ NETO, A. F.; ROCHA, G. C. Área foliar específica e anatomia foliar quantitativa do capimbraquiária e do amendoim-forrageiro submetidos a sombreamento. Revista Brasileira de Zootecnia, v. 40, n. 7, p. 1436-1444, 2011.

KIRST, H.; GABILLY, S; T; NIYOGI, K. K.; LEMAUX, P. G.; MELIS, A. Photosynthetic antenna engineering to improve crop yields. Planta, v. 245, n. 5, p. 1009-1020, 2017. 
LI, Y.; REN, B.; GAO, L.; DING, L.; JIAND, D.; XU, X. Less chlorophyll does not neessarily restrain light capture ability and photosynthesis in a chlorophyll-deficient rice mutant. Journal of Agronom and Crop Science, v. 199, p. 49-56, 2013.

LOBO, F. A.; ORTÍZ, C. E. R.; LUCENA, I. C.; ARDUIN, M. Efeito da irrigação e da ontogenia sobre a estimativa da área foliar de Hancornia speciosa Gomez (Mangabeira). Revista Brasileira de Fruticultura, Jaboticabal, v. 32, n. 3, p. 754-762, 2010.

MACHADO, R.S.; RIBEIRO, R.V.; MARCHIORI, P. E. R.; MACHADO, D. F. S. P.; MACHADO, E. C.; LANDELL, M. G. A. Respostas biométricas e fisiológicas ao déficit hídrico em cana-de-açúcar em diferentes fases fenológicas. Pesquisa Agropecuária Brasileira, Brasília, v. 44, p. 1575-1582, 2009.

MARTINS, A. C. F.; SCHIAVINI, I.; ARAÚJO, G. M.; LOPES, S. F. Capacidade adaptativa de espécies do cerrado utilizadas em áreas de recuperação ambiental. Revista Árvore, Viçosa-MG, v. 39, n. 3, p. 543-550, 2015 .

MARTINS, G. A. Avaliação de características de estômatos em jatobá (Hymenaea courbaril L.) com uso da geoestatística. 2009. 73 f. (Mestrado em Fisiologia Vegetal) - Universidade Federal de Lavras, Lavras-MG.

PALHARES, D.; FRANCO, A. C.; ZAIDAN, L. B. P. Respostas fotossintéticas de plantas e cerrdo nas estaçoes seca e chuvosa. Revista Brasileira de Biociências, Porto Alegre, v. 8, n. 2, p. 213-220, 2010.
PILON, N. A. L.; UDULUTSCH, R. G.; DURIGAN, G. Padrões fenológicos de 111 espécies de Cerrado em condições de cultivo. Hoehnea, v. 42, n. 3, p. 425-443, 2015.

PRADO JÚNIOR, J. A. Traços funcionais como preditores da similaridade funcional entre subbosques de florestas estacionais semideciduais: subsídios para a conservação destes ecossistemas. 2012. 84 f. (Mestrado em Biologia Vegetal) Universidade Federal de Uberlândia, Uberlândia, Minas Gerais.

QADERI, M. M.; KUREPIN, L. V.; REID, D. M. Effects of temperature and watering regime on growth, gas exchange and abscisic acid content of canola (Brassica napus) seedlings. Environmental and Experimental Botany, Elmsford, v. 75, p. 107-113, 2012.

SAGE, R. F.; KUBIEN, D. S. The temperature response of C3 and C4 photosynthesis. Plant, Cell and Environment, New York, n. 30, p. 1086-1106, 2007. SILVA, A. R. A.; BEZERRA, F. M. L.; LACERDA, C. F.; PEREIRA FILHO, J. V.; FREITAS, C. A. S. Trocas gasosas em plantas de girassol submetidas à deficiência hídrica em diferentes estádios fenológicos. Revista Ciência Agronômica, v. 44, n. 1, p. 86-93, 2013. 